\title{
Depressive symptoms in opiate addicts on methadone maintenance
}

\author{
*Hugh Williams, MB, MRCPsych. John J. O’Connor, MB, MRCPsych, Drug Treatment Centre, Trinity Court. 30-31 Pearse \\ Street, Dublin 2. \\ Anthony Kinsella, MSc, Department of Mathematics, Dublin Institute of Technology, Kevin Street, Dublin 2. \\ *Correspondence
}

\begin{abstract}
Sixty seven opiate dependent addicts receiving methadone maintenance completed the Beck Depression Inventory. A high level of depressive symptoms was found. Eighteen (27\%) scored in the moderately depressed range while thirty eight $(56 \%)$ scored in the severely depressed range. There was no statistically significant association between either sex or HIV status and level of symptom reporting. The clinical implications of depressive symptoms in opiate addicts are discussed.
\end{abstract}

Key Words: Opiate dependency, Depression, Beck Depression Inventory, Human Immunodeficiency Virus (HIV).

\section{Introduction}

A number of studies have shown association between drug dependence and other psychiatric disorders. In a large survey of opiate addicts, Rounsaville et $a l^{1}$ found that $70 \%$ had at least one other current psychiatric diagnosis in addition to their drug dependence. The most common diagnoses (using Research Diagnostic Criteria) were major depressive disorders, alcoholism and antisocial personality. More than two thirds had either chronic or episodic depressive disorders. Using the Beck Depression Inventory (B.D.I.), Dorus and Senay $^{2}$ found $46 \%$ of a sample of 432 substance abusers reported moderate or high levels of depressive symptoms. The majority of the subjects were opiate dependent. Among 100 male heroin addicts attending for methadone maintenance, Shaw $e l a l^{3}$ reported that $60 \%$ had at least mild levels of depressive symptoms on the B.D.I. To our knowledge the above-findings $\mathrm{s}^{1,2,3}$, have not been replicated among Irish opiate addicts.

The present study reports on the level of depressive symptomatology reported by a sample of opiate addicts attending the Drug Treatment Centre in Dublin who were receiving Methadone maintenance therapy.

\section{Method}

All those opiate addicts attending the Drug Treatment Centre at the start of November 1988 who were receiving methadone maintenance were selected for inclusion in the study $(\mathrm{N}=70)$. All met DSM-3 diagnostic criteria for opiate dependence. ${ }^{4}$ Patients receiving methadone maintenance are in general those who, despite repeated detoxification, fail to remain abstinent and/or those addicts who experience the additional difficulty of coping with being sero-positive for HIV (Human Immunodeficiency Virus). Pregnant opiate addicts are maintained on a low dose methadone regime during pregnancy. Such patients attend the clinic on a daily basis for methadone (physeptone linctus - average daily dosage $30 \mathrm{mg}$ daily) and for supervised urinalysis. They participate in group therapy, occupational therapy and receive individual counselling. They are seen regularly by a psychiatrist. Family members attend a support group and special facilities are available for addicted mothers and their children.

All 70 patients on methadone maintenance were asked to participate, and none refused. All met the study's inclusion criteria, namely, evidence of opiate dependency, attendance at the clinic at the start of the study period and receiving methadone maintenance-One patient was subsequently excluded as he dropped out of treatment. Sixty nine individuals completed the B.D.I.; however, two did so incompletely. The Beck Depression Inventory is a 21-item self report questionnaire that measures various symptoms of depression. ${ }^{5}$ Scores 0-15 indicate no or mild levels of depression; scores of 16-23 indicate moderate depression while scores above 24 indicate severe depression. The final number of patients who fully completed the B.D.I. was sixty seven $(\mathrm{N}=67), 36$ were males, 31 females.

A separate questionnaire was also completed on the same sample of patients $(\mathrm{N}=69)$. This questionnaire was formulated to gather standardised information on sociodemographic details, medical complications and drug histories. It also included questions on sexual and needle sharing practices. The results form part of a separate study in progress. For the purpose of the present paper a brief profile of the patients is presented (Table 1).

TABLE 1

\begin{tabular}{|c|c|c|}
\hline \multicolumn{3}{|c|}{$\begin{array}{l}\text { Profile of Opiate Addicts on Methadone Maintenance at the Drug } \\
\text { Treatment Centre }(\mathrm{N}=69)\end{array}$} \\
\hline 1. & Age: 27.8 y (mean) (S.D. 4.9y) Range (1 & 39 y) \\
\hline 2. & Marital Status: & $\begin{array}{l}\text { Single: } 32 \% \\
\text { Married: } 16 \% \\
\text { Common Law: } 42 \% \\
\text { Separated: } 10 \%\end{array}$ \\
\hline 3. & Local Authority Housing: & $86 \%$ \\
\hline 4. & $\begin{array}{l}\text { Poor Education (no formal } \\
\text { examinations): }\end{array}$ & $71 \%$ \\
\hline 5. & Unemployed (for last 2 years) & $87 \%$ \\
\hline 6. & Parental History of Alcoholism: & $35 \%$ \\
\hline 7. & Parental History of Psychiatric Illness: & $20 \%$ \\
\hline 8. & Sibling abusing drugs: & $49 \%$ \\
\hline 9. & Served prison sentence: & $74 \%$ \\
\hline 10. & Medical Complications: Hepatitis & $59 \%$ \\
\hline 11. & Age first used drugs (excl. alcohol): & 15.8 y (mean) \\
\hline 12. & Age first presented for treatment: & 20.5 y (mean) \\
\hline & $\begin{array}{l}\text { Drugs first used (excl. alcohol): } \\
\text { Cannabis } \\
\text { Opiates }\end{array}$ & $\begin{array}{l}48 \% \\
32 \%\end{array}$ \\
\hline
\end{tabular}

This article is a reproduction of that published in: Irish Journal of Psychological Medicine, 7(1), March, 1990, pp.45-46.. Pagination may not match that of the original. 


\section{Results}

The mean score on the B.D.I, for the group as a whole was 25.7 (S.D. 11). Eleven (16.4\%) of the sample reported symptoms in the no depression or mild depression range. Eighteen $(26.9 \%)$ scored in the moderate depression range while thirty eight $(56.7 \%)$ had scores indicative of severe depressive symptoms. The results cross tabulated by sex are summarised in Table 2 .

TABLE 2

\begin{tabular}{llll}
\hline \multicolumn{4}{c}{ B.D.I. Scores and Sex } \\
\hline Score & $\begin{array}{l}\text { Male } \\
\text { n (\%) }\end{array}$ & $\begin{array}{l}\text { Female } \\
\text { n (\%) }\end{array}$ & $\begin{array}{l}\text { Both Sexes } \\
\text { N (\%) }\end{array}$ \\
\hline $0-15$ & $5(13.9 \%)$ & $6(19.4 \%)$ & $11(16.4 \%)$ \\
$16-23$ & $10(27.8 \%)$ & $8(25.8 \%)$ & $18(26.9 \%)$ \\
$24+$ & $21(58.3 \%)$ & $17(54.8 \%)$ & $38(56.7 \%)$ \\
All Scores & $36(100.0 \%)$ & $31(100.0 \%)$ & $67(100.0 \%)$
\end{tabular}

Chi-squared test value, $X^{2}=0.36 ; d f=2 ; p=0.83$.

Non-significant.

In view of the high rate of HIV infection (48/69) in the study group the scores on the B.D.I, were also cross tabulated with H.I.V. status (Table 3). HIV negative status included sixteen patients known to be HIV negative and five patients whose HIV status was unknown (not tested).

TABLE 3

\begin{tabular}{llll}
\hline & \multicolumn{3}{c}{ B.D.I. Scores and H.I.V. Status } \\
\hline \multicolumn{1}{c}{ Score } & \multicolumn{1}{c}{ HIV Positive } & HIV Negative & Either HIV Status \\
& \multicolumn{1}{c}{ n (\%) } & \multicolumn{1}{c}{ n (\%) } & N (\%) \\
\hline $0-15$ & $6(13.0 \%)$ & $5(23.8 \%)$ & $11(16.4 \%)$ \\
$16-23$ & $11(23.9 \%)$ & $7(33.3 \%)$ & $18(26.9 \%)$ \\
$24+$ & $29(63.0 \%)$ & $9(42.9 \%)$ & $38(56-7 \%)$ \\
All Scores & $46(100.0 \%)$ & $21(100.0 \%)$ & $67(100-0 \%)$ \\
\hline
\end{tabular}

Chi-squared lest value, $X^{2}=2.53 ; d f=2 ; p=0.28$.

Non-significant

No significant association was found between B.D.I. scores and HIV status or sex.

\section{Discussion}

In the present study $83 \%$ of the sample reported depressive symptoms in the moderate or severe range of the B.D.I. The results are in keeping with other studies which have found notable levels of depression in opiate addicts. More wide ranging conclusions or comparisons cannot be claimed from the present paper. The subjects were opiate addicts in treatment and therefore not representative of addicts in the community or other populations of opiate abusers.

The relationship between depression and opiate dependence in this group is likely to be complex and multifactorial. It has been suggested that opiate use may be a method of self medication to relieve depressive feelings. Conversely dysphoric mood may result from long term opiate abuse. The depressive symptoms reported by the group could represent a reaction to a difficult life situation (unemployment, poor housing, low level of education etc.), Table 1. Their opiate dependence could be regarded as another aspect of a generalised deprived and delinquent lifestyle. It is also possible that the depression could be explained on the basis of familial factors. Thirty five percent of the sample has a parent with alcoholism and twenty per cent of the parents had received treatment in a clinic or psychiatric hospital for other psychiatric disorders.

The psychiatric complications of HIV infection have been well described and depressive symptoms are common. ${ }^{6,7,8}$ Seventy percent were sero-positive, but-no statistically significant relationship was found between B.D.I, scores and HIV status. Caution must be exercised in interpreting these results (Table 3). Five individuals (5/21) of the sero-negative group had not been tested for antibodies to the HIV. Fear and uncertainty surrounding the possibility of being infected are likely to give rise to increased symptom reporting. If we allow for these individuals there still remains no statistically significant difference between the two groups. However, the number in each group is small. The high rate of sero-positivity in the study group may be explained by the clinics policy of more readily offering maintenance programmes to HIV positive addicts.

Despite uncertainty concerning their nature and their relationship to dependence, depressive symptoms in opiate addicts have some important clinical and treatment implications. A sizable proportion of the sample (48\%'o, unpublished data) had overdosed while injecting illicit drugs. Some of these episodes may not have been accidental. Furthermore, a recent study has drawn attention to the importance of negative mood states as precipitants of relapse in opiate addicts following treatment. ${ }^{9}$ It is therefore important to recognise and treat mood disturbance in opiate addicts. With regard to anti-depressive treatment care must be exercised. Compliance with prescribed medication is often poor and there is always the possibility of dangerous interaction between prescribed methadone or illicit opiates and anti-depressants.

In conclusion, the opiate addicts studied had a high level of depressive symptoms as measured by the B.D.I The relationship between depression and opiate dependency in the group studied is speculative, and open to various interpretations. However, awareness and recognition of depressive symptoms have an important bearing on the effective treatment of opiate dependent individuals.

\section{Acknowledgements:}

We would like to thank Ms. Siobhan Fisher and Ms. Fionnuala Rafferty for their help in typing the manuscript.

\section{References}

1. Rounsaville BJ, Weissman MM, Kelber H, Wilber C. Heterogeneity of psychiatric diagnosis in treated opiate addicts. Arch Gen Psychiatry 1982; 39: 161-166.

2. Dorus W, Senay EC. Depression, demographic dimensions, and drug abuse. Am J Psychiatry 1980: 137: 699-704.

3. Shaw BF, Steer RA. Beck AT, Schut J. The structure of depression in heroin addicts, $B r J$ Addict 1979; 74: 295-303.

4. American Psychiatric Association. Diagnostic and statistical manual of mental disorders. 3rd ed. Washington, D.C.: APA, 1980.

5. Beck AT, Ward CH, Mendelson M, Mock J, Erbaugh J. An inventory for measuring depression. Arch Gen Psychiatry 1961; 4: 561-571.

6. Fenton TW. A.I.D.S. - related psychiatric disorder. Br J Psychiatry 1987; 151 579-588.

7 Fenton TW. Psychiatric aspects of H.I.V. infection. Journal of the Royal College of Physicians of London 1988; 22: 145-148.

8. Dilley JW. Psychiatric sequeli of H.I.V. In: Paine L, ed. A.I.D.S., psychiatric and psychosocial perspectives. Croom Helm, 1988: 25-44.

9. Bradley PB, Phillips G, Green L, Gossop M. Circumstances surrounding the initial lapse to opiate use following detoxification. $B r J$ Psychiatry 1989; 154: 354-359. 